\title{
Retrofit of the Heat Recovery System of a Petroleum Refinery Using Pinch Analysis
}

\author{
John M. Joe, Ademola M. Rabiu \\ Department of Chemical Engineering, Cape Peninsula University of Technology, Cape Town 8001, South Africa. \\ Email: JohnJ@cput.ac.za
}

Received September 2013

\begin{abstract}
Energy efficiency has become an important feature in the design of process plants with the rising cost of energy and the more stringent environmental regulations being implemented worldwide. In South Africa, as elsewhere, most process plants built during the era of cheap energy place little emphasis on the need for energy recovery due to the abundance of cheap utilities sources such as coal. In most of these plants, there exist significant potential for substantial process heat recovery by conceptual design of the heat recovery system. By maximizing heat recovery from the processes, there will be a reduction in the process utilities requirement and the associated environmental effects. Pinch analysis has been demonstrated to be a simple but very effective tool for heat integration and optimization of chemical plants. This study uses the pinch principle to retrofit the heat exchanger networks (HEN) of the crude distillation unit of an integrated petroleum refinery to evolve a HEN that features optimum energy recovery. The network was further relaxed by trading off energy cost with capital cost to obtain an optimal HEN topology not too different from the existing network. The simulation works were implemented in AspenPlus v8.0 environment. Analysis revealed that 34 per cent saving on energy usage per annum is realizable. This significant saving in energy also results in diminished gaseous pollutants associated with energy usage.
\end{abstract}

Keywords: Plant Retrofit; Heat Integration; Crude Distillation Unit; Heat Exchanger Network; Pinch Analysis; Optimization; Remaining Problem Analysis

\section{Introduction}

The issues of energy sustainability and security [1] and the increasingly stringent environmental regulations have combined to elevate the challenge of energy efficiency to a high-priority issue [2] for energy intensive industries. It was reported that the Chinese petroleum refining industry consumes approximately $15 \%$ of industrial fuel oil and $10 \%$ of industrial coal [3]. Plants retrofitting towards cost-effective energy recovery and hence improved energy and utilities usage become attractive and are being implemented worldwide. It has become imperative to improve on the overall economic and environmental footprints of existing plants to enhance their competitiveness [3] as well as sustainability. The ultimate aim is to synthesize a process that is cost-effective and environmentally benign [4]. It is expected that many process plants in South Africa have inefficient heat recovery system. Before the energy crisis, the chemical industries saw little use of heat integration to reduce energy usage, since energy (particularly from fossil fuels) was relatively inexpensive and abundant [5]. Little emphasis was placed on optimal process heat recovery because of the cheap availability of utilities sources at the time of plant construction. The sharp rise in fuel price, dwindling fossil fuels reserves, and the growing awareness of the environmental problems associated with fossil fuels consumption, have however combined to drive the impetus for design of energy efficient plant [6]. Analyses of the energy recovery system of plants design with rule of thumbs have revealed potential significant savings in utilities usage [7, 8] by placing better matches between the process streams. A design that maximizes energy recovery using heat exchanger networks to match the process hot and cold streams, will result in minimal external heating and cooling requirements to meet the energy needs of the plant. For instance, Kemp [9] reported a potential saving of between 30 to 100 per cent in utilities usage in various units of a petroleum refinery.

This study is motivated by the need to improve on the energy efficiency of petroleum refineries designed with rule of thumbs available at the time, by modifying the existing heat exchanger networks and hence saving on utilities usage and the emission of greenhouse gases from fossil fuels consumption. The Crude Distillation Unit (CDU) 
[10] consumed the most energy in a refinery, consuming as much as 2 per cent of the total crude oil processed [11]. It is therefore expected that the use of PT to analyze the energy recovery system of the CDU will reveal better matches for process energy transfer, and hence saves on utilities usage and the associated environmental benefits, for instance, the emission of obnoxious pollutants. It investigated the potential saving in utility usage in the crude distillation unit of a petroleum refinery. A preliminary energy audit of the plant was carried out using AspenPlus v8.0 to locate the unit with highest utility requirement and offers the most potential energy savings. The Remaining Problem Analysis (RPA) variant of the Pinch Technology was applied to locate and reassigned only the heat exchangers that are inefficiently placed.

\section{Process Heat Integration}

A design of an efficient and cost effective process heat recovery system employing series of heat exchangers will promote efficient utilities usage and requirement leading to savings in energy cost [12]. The practical importance of HENs can be found in the fact that most industrial processes involve transfer of heat, either from one process stream to another process stream or from a utility stream to a process stream $[13,14]$. Consequently, the target in any industrial process design is to maximize the processto-process heat recovery and to minimize the utility requirements. To meet this goal, cost-effective HEN consisting of one or more heat exchangers that collectively satisfy the energy conservation task, is of particular importance.

The use of Pinch Technology (PT) for retrofitting and grassroot designs, has been found to result in considerable saving for instance in energy usage. This saving directly improves the economics of the plant. Pinch technology is one of the least complicated and most effective technologies for Heat Exchanger Networks (HEN) design in the energy recovery and optimisation of energy within the chemical plant. It is based on sound thermodynamic principles without including heavy mathematical calculations and interpretations. The use of pinch technology for plant modification is centered on the trade-off between the savings in utilities versus the cost of the proposed changes in the plant. The "pinch" point represents the bottleneck of heat recovery. The key concept of pinch analysis is the setting of energy targets [9] with the aim to achieve maximum energy saving by maximising process to process heat recovery and minimising the use of hot and cold utilities.

\section{Methods}

\subsection{Data Extraction and Energy Target}

The design and operating data of the refinery unit were obtained. A detailed modelling and simulation of the unit was carried out in AspenPlus v8.0 environment for convergence test to reconcile the streams enthalpy data. The enthalpy data required were extracted. This was done in order to scope the existing network for potential energy and cost savings. Thermodynamic profiles of the process streams using the Problem Table algorithms, Composite Curves and Grand Composite Curves were studied to determine the targets for the hot and cold utilities and the position of the pinch. This profile also indicated the maximum energy recovery possible at the chosen $\Delta \mathrm{T}_{\text {min.. }}$

\subsection{Maximum Energy Recovery Network Design}

The existence of a topology trap was first investigated by studying the influence of $\Delta \mathrm{T}_{\min }$ on the utilities requirement. This is also used to obtain an optimum $\Delta \mathrm{T}_{\min }$ for the retrofitting study.

To achieve the target obtained above, a new heat exchanger network featuring maximum energy recovery (MER) was obtained using the remaining problem analysis approach as developed by Tjoe and Linnhoff [15]. Retroffiting of HEN is agreed upon (for instance [5]) to be more tasking than grassroot design. For the results of the retrofit project to be implementable, the resulting networks while featuring significant energy savings must not be markedly different from the existing networks. Otherwise the modification required will be major and costly offsetting the targeted saving in energy cost. Remain problem analysis as a technique for retrofitting of the HEN is an essential principle to develop an optimized HEN close to the existing plant topology. This is necessary because of layout considerations and the cost implications of matches.

The methodology will keep as much as possible to the existing topology of the plant, meaning the exchangers that did not violate the pinch were left untouched. This entails identifying the heat exchangers working across the pinch and hence inefficiently placed or streams that were inefficiently matched while leaving the other heat exchangers intact. The objective of the evaluation of the existing network was to use the existing area within this network more effectively. This was done to identify the area used due to criss-crossing [15]. The new network features maximum energy recovery.

\subsection{MER Network Relaxation}

An optimization of the process was done for possible network relaxation. A trade-off looking at the existing process and the MER design was carried out focusing on the investment and energy costs. The MER network was examined for possible network simplification, by identifying and removing loops to trade-off capital cost of the required heat transfer unit and energy cost of the saved 
utilities. This eventually entails reducing the number of the heat transfer unit thus reducing capital costs while sacrificing some energy recovery. A comparison of the cost implications of the various networks was presented.

\section{Results}

The composite curve from the enthalpy data is presented in Figure 1. From the composite curve, it could be seen that the overlapping of the cold composite and the hot composite curve indicates a high possibility of process to process heat exchange. The minimum utilities requirements for the plant are $72 \mathrm{MW}$ and $64 \mathrm{MW}$ for the hot and cold utility respectively at a $\Delta \mathrm{T}_{\min }$ of $15^{\circ} \mathrm{C}$. This presented about 34 per cent potential reduction in utility requirement. There is only one pinch point, $235^{\circ} \mathrm{C}$ and $225^{\circ} \mathrm{C}$ for hot and cold streams respectively.

In Figure 2, the plot of the cold and hot utilities at different $\Delta \mathrm{T}_{\min }$ shows a linear relationship with no discontinuity within the range. This signified the absence of a topology trap. The absence of a topology trap means that the need for a detailed cost analysis to determine the optimum $\Delta \mathrm{T}_{\min }$ using different algorithms and graphs is not necessary.

The grid diagram for the existing network is presented in Figure 3. It shows that seven exchangers are working across the pinch. Hence, there is no maximum energy recovery and there is no efficient use of the existing heat exchangers.

The focus of the study is concentrated only re-assign- ing these exchangers. Using the remaining problem analysis approach, the network in Figure 4 was obtained. The complete heat exchanger network design represents maximum energy recovery of the process heat utilizing as many as required heat transfers unit including heat exchangers, heaters/furnace and coolers. This network realised the utilities targets set above.

The relaxation process of the network is an important part in the optimization of the network. The purpose of this step is not to eliminate all the loops and paths but to rather reduce the paths and loops. This step involves the removal of heat exchangers by allowing a small energy penalties leading to a reduction of units within the network thus reducing capital costs. The ultimate aim is to find a balanced heat exchanger network, keeping as best as possible the topology maximising the energy duties between the streams whilst not incurring heavy capital costs related to the heat exchanger areas. This network has minimum impact on the current configuration of the plant, whist giving a substantial 34 per cent saving on utilities.

In the MER network, there are a number of loops and paths, the target of the relaxation step for this design is not to remove some or all of these loops and paths. The final relaxed network is presented in Figure 5. This network has six less heat transfer unit compared to the MER design.

The cost implication of the various networks is as presented in Table 1.

Hot and Cold Composite Curves

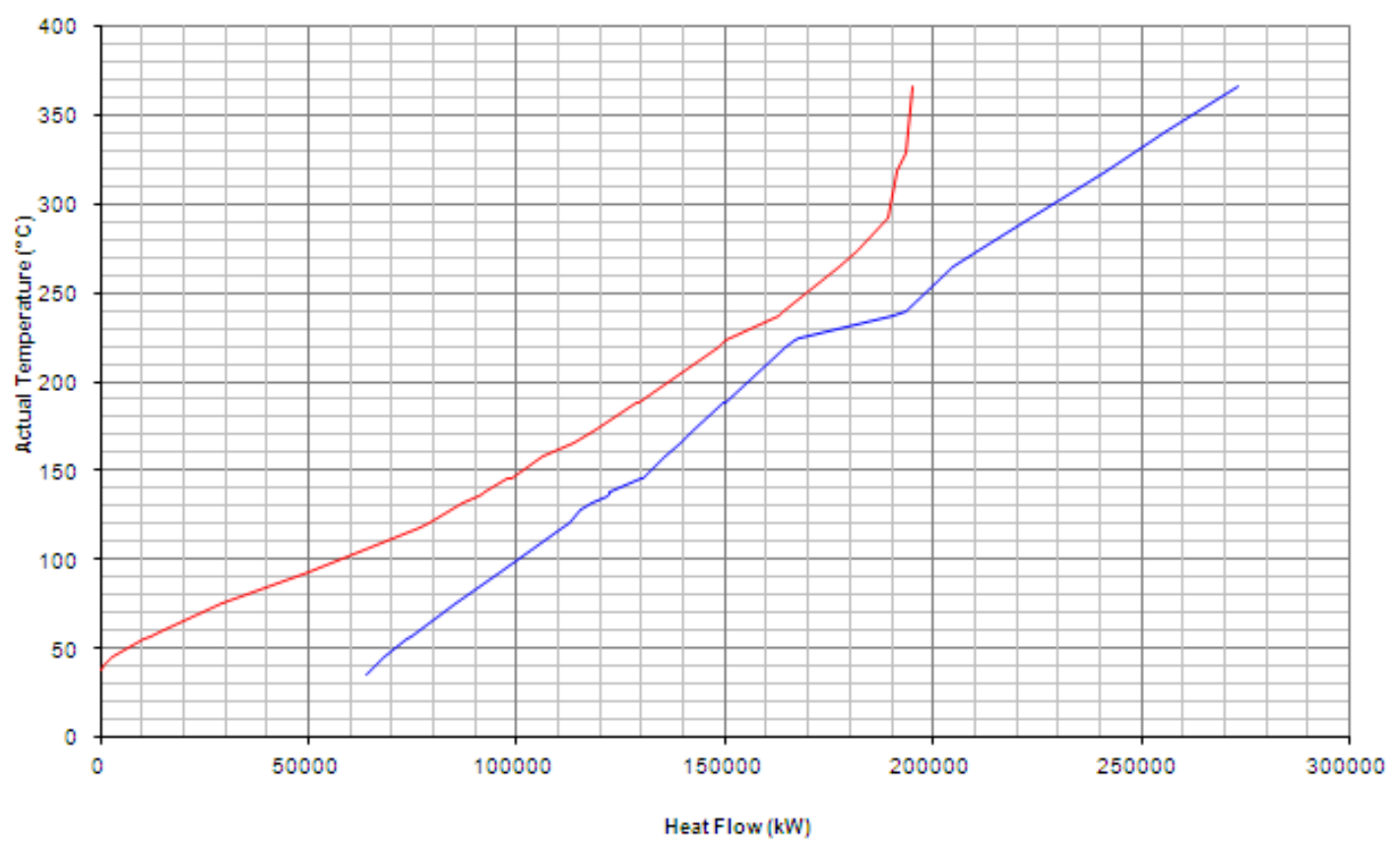

Figure 1. The composite curve at $\Delta T_{\min }$ of $15^{\circ} \mathrm{C}$. 


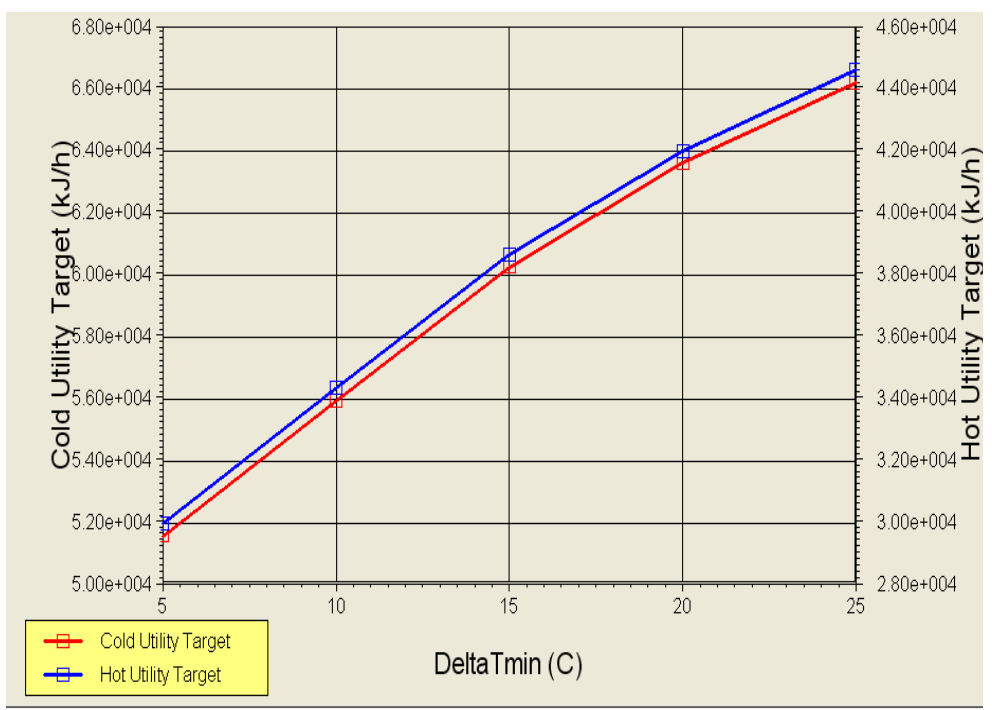

Figure 2. Plot of the utility requirements vs $\Delta \mathbf{T}_{\min }$.

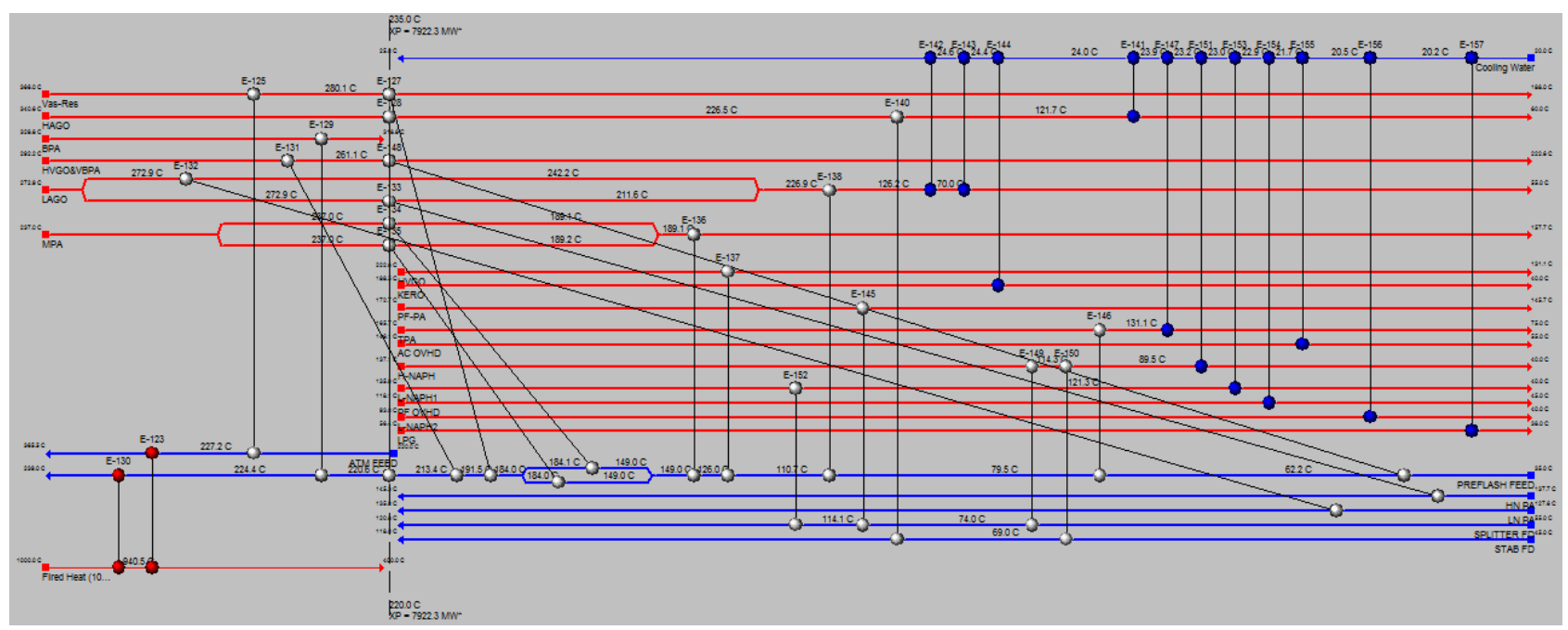

Figure 3. The existing heat exchanger network showing across the pinch violation.

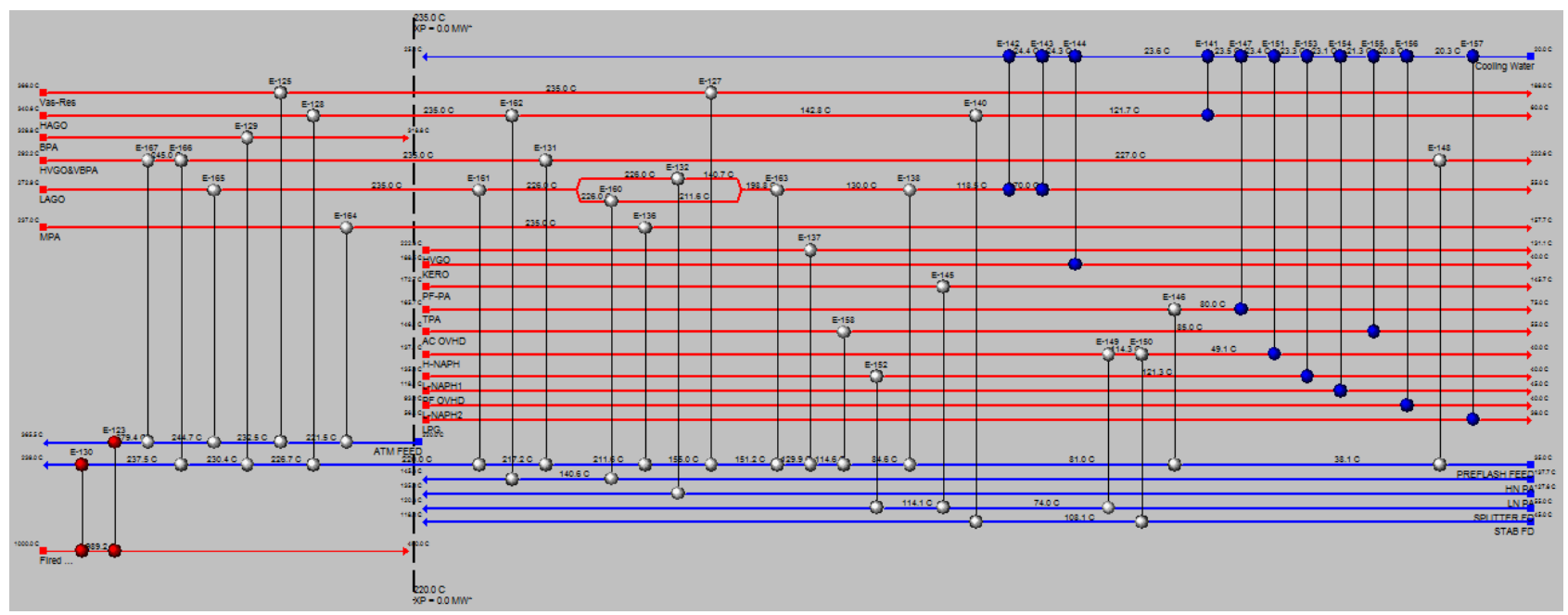

Figure 4. The maximum energy recovery network. 


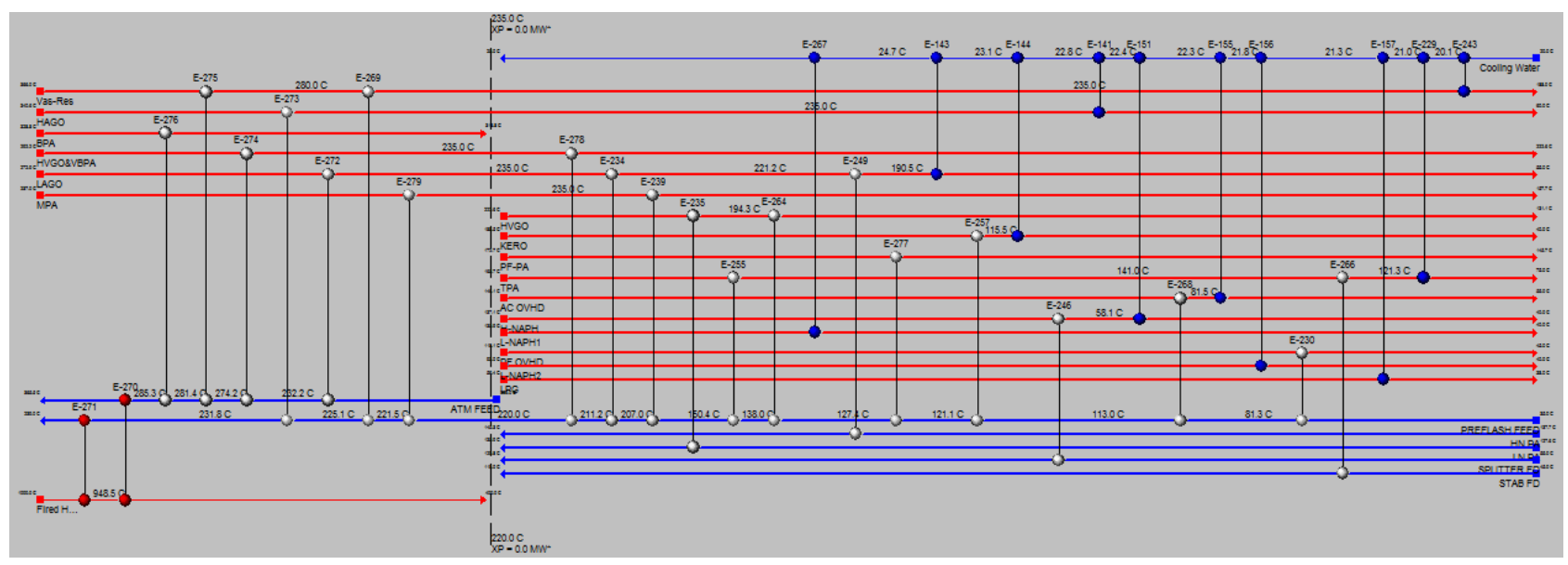

Figure 5. The final relaxed network.

Table 1. Cost comparisons of the heat exchanger networks.

\begin{tabular}{cccc}
\hline HEN Description & Existing HEN & MER Network & Final Relaxed HEN \\
\hline Utility Costs (\$) & 222,536 & 115,670 & 149,954 \\
Capital Cost (Heat exchangers) (\$) & 865,045 & $1,199,490$ & $1,010,176$ \\
Capital Cost (Furnace, Coolers) (\$) & 589,367 & 542,373 & 497,866 \\
\hline
\end{tabular}

\section{Conclusion}

In the current economic climate, with the rising cost of fuel that provides the industrial plants with their heating and cooling needs, it has become imperative that the plant becomes more energy efficient. This study confirmed that Pinch Technology is a very practical, easy and intuitive method for attaining better process heat integration. The existing HEN had a number of heat exchangers working across pinch; these violations were eliminated during the retrofitting. The final evolved HEN reveal a potential 34 per cent energy saving in the plant section studied. A trade-off was explored to find a balance of utilities usage, number of exchanger units and area. This was done by using the heat load loops and paths. The effect of pressure in the evolved HEN network was not investigated. This must be considered before implementing the recommendations. Alternative methods must also be used to verify the findings of this study such as mathematical optimisation methodologies. In conclusion, pinch technology is still an important method for evaluating and scoping for potential energy saving in a chemical plant. It is particularly relevant today, due to the high cost of utilities and the adverse environmental impact of energy usage by industries.

\section{Acknowledgements}

The authors acknowledge the supports provided by Cape Peninsula University of Technology, Nigerian National Petroleum Corporation (NNPC) and the management of Warri Refinery and Petrochemical Complex, Nigeria.

\section{REFERENCES}

[1] D. S. Selvakkumaran and B. Limmeechokchai, "Energy Security and Co-Benefits of Energy Efficiency Improvement in Three Asian Countries," Renewable and Sustainable Energy Reviews, Vol. 20, 2013, pp. 491-503.

[2] D. von Hippel, T. Suzuki, J. H. Williams, et al., "Energy Security and Sustainability in Northeast Asia," Energy Policy, Vol. 39, No. 11, 2011, pp. 6719-6730. http://dx.doi.org/10.1016/j.enpol.2009.07.001

[3] X. Liu, D. Chen, W. Zhang et al., "An Assessment of the Energy-Saving Potential in China's Petroleum Refining Industry from a Technical Perspective,” Energy, Vol. 59, 2013, pp. 38-49.

[4] M. M. El-Halwagi, "Chapter 22-Macroscopic Approaches of Process Integration,” Sustainable Design through Process Integration, Butterworth-Heinemann, Oxford, 2012, pp. 375-391.

http://dx.doi.org/10.1016/B978-1-85617-744-3.00022-9

[5] Y. Kansha, A. Kishimoto and A. Tsutsumi, “Application of the Self-Heat Recuperation Technology to Crude Oil Distillation,” Applied Thermal Engineering, Vol. 43, 2012, pp. 153-157.

http://dx.doi.org/10.1016/j.applthermaleng.2011.10.022

[6] H. Zhang and G. P. Rangaiah, “One-Step Approach for Heat Exchanger Network Retrofitting Using Integrated Differential Evolution,” Computers \& Chemical Engineering, Vol. 50, 2013, pp. 92-104.

http://dx.doi.org/10.1016/j.compchemeng.2012.10.018

[7] M. Escobar and J. O. Trierweiler, "Optimal Heat Exchanger Network Synthesis: A Case Study Comparison,” Applied Thermal Engineering, Vol. 51, No. 1-2, 2013, pp. 801-826.

http://dx.doi.org/10.1016/j.applthermaleng.2012.10.022 
[8] M. Gorji-Bandpy, H. Yahyazadeh-Jelodar and M. Khalili, "Optimization of Heat Exchanger Network," Applied Thermal Engineering, Vol. 31, No. 5, 2011, pp. 779-784. http://dx.doi.org/10.1016/j.applthermaleng.2010.10.026

[9] I. C. Kemp, "Pinch Analysis and Process Integration-A User Guide on Process Integration for the Efficient Use of Energy,” Butterworth-Heinemann, 2007.

[10] M. Gadalla, D. Kamel, F. Ashour and H. M. El Din, “A New Optimisation Based Retrofit Approach for Revamping an Egyptian Crude Oil Distillation Unit,” Energy Procedia, Vol. 36, 2013, 2013, pp. 454-464.

[11] M. Errico, G. Tola and M. Mascia, "Energy Saving in a Crude Distillation Unit by a Preflash Implementation," Applied Thermal Engineering, Vol. 29, No. 8-9, 2009, pp. 1642-1647.

http://dx.doi.org/10.1016/j.applthermaleng.2008.07.011

[12] S. Sieniutycz and J. Jeżowski, “12-Heat Integration with- in Process Integration," Energy Optimization in Process Systems and Fuel Cells, 2nd Edition, Elsevier, Amsterdam, 2013, pp. 465-474.

http://dx.doi.org/10.1016/B978-0-08-098221-2.00012-6

[13] P. Rašković and S. Stoiljković, "Pinch Design Method in the Case of a Limited Number of Process Streams," Energy, Vol. 34, No. 5, 2009, pp. 593-612. http://dx.doi.org/10.1016/j.energy.2008.04.004

[14] S. Sieniutycz and J. Jeżowski, "13-Maximum Heat Recovery and Its Consequences for Process System Design," Energy Optimization in Process Systems and Fuel Cells, 2nd Edition, Elsevier, Amsterdam, 2013, pp. 475-497. http://dx.doi.org/10.1016/B978-0-08-098221-2.00013-8

[15] T. N. Tjoe and B. Linnhoff, "Using Pinch Technology for Process Retrofit,” Chemical Engineering, 1986, pp. 4760. 